\title{
Magnetic properties of the Wenchuan Earthquake Fault Scientific Drilling Project Hole-1 (WFSD-1), Sichuan Province, China
}

\author{
Junling Pei ${ }^{1 *}$, Haibing $\mathrm{Li}^{2}$, Huan Wang ${ }^{2}$, Jialiang Si ${ }^{2}$, Zhiming Sun ${ }^{1}$ and Zaizheng Zhou ${ }^{1}$
}

\begin{abstract}
We measured the magnetic susceptibility of the core from the first borehole of the Wenchuan Earthquake (May 12, 2008, Mw7.9) Fault Scientific Drilling Project (WFSD-1) at 1-cm intervals. The correlations between magnetic susceptibility anomalies and fault rock occurrence are shown by a few fault zones in the WFSD-1 core. The values for the mass and ferromagnetic material magnetic susceptibility for the sample at 589.25-m depth are higher than those for the other samples. All the thermomagnetic curves display a rapid increase in slope after $380^{\circ} \mathrm{C}$, and a marked peak occurs at about $510^{\circ} \mathrm{C}$ in the heating curves. The cooling curves are clearly higher than the heating curves. The saturation magnetization (Ms) shows a significant peak at a depth of $589.25 \mathrm{~m}$, as do the mass magnetic susceptibility and the ferrimagnetic magnetic susceptibility. The mechanism principally responsible for the high magnetic susceptibility at a depth of $589.25 \mathrm{~m}$ might be the production of new magnetite from iron-bearing silicates (e.g., chlorite) or clays caused by frictional heating during seismic slip. Therefore, we suggest that the presence of high magnetic susceptibility fault gouges in the same country rock can be considered as an indicator of earthquakes or seismic signatures.
\end{abstract}

Keywords: Wenchuan Earthquake; Yingxiu-Beichuan fault; Slip zone; Magnetic susceptibility

\section{Background}

The magnetic properties of fault rocks can be used as tracers for physical and chemical alterations caused by frictional heating during earthquakes. Magnetic susceptibility and rock magnetism have commonly been used to understand the physical characteristics and chemical processes of fault slip zones (Enomoto and Zheng 1998; Nakamura and Nagahama 2001; Ferré et al. 2005, 2012). Correlations have been reported between magnetic susceptibility anomalies in borehole log data and the presence of cataclastic zones and faults in the main drill borehole of the German Deep Drilling Project (KTB) (Bosum et al. 1997), but the magnetic susceptibility of drill cuttings in the KTB do not support this correlation (Rauen et al. 2000). A series of studies demonstrated that higher magnetic susceptibilities might result from the production of new magnetic minerals with high

\footnotetext{
* Correspondence: jlpei@qq.com

${ }^{1}$ Key Laboratory of Paleomagnetism and Tectonic Reconstruction of Ministry of Land and Resources, Institute of Geomechanics, Chinese Academy of Geological Sciences, Beijing 100081, China

Full list of author information is available at the end of the article
}

magnetic susceptibility caused by frictional heating (Hirono et al. 2006; Mishima et al. 2006; Tanikawa et al. 2008) or from decreases in the grain size of magnetic minerals caused by shearing (Dearing 1999) during large-magnitude earthquakes (e.g., the Kobe and Chi-Chi earthquakes). Recently, the Chi-Chi earthquake gouge layer has been identified from the modern geomagnetic field direction recorded within the gouge layer (Chou et al. 2012).

Motivated by an interest in investigating the mechanism of the 2008 Wenchuan Earthquake, the Wenchuan Earthquake Fault Scientific Drilling Project (WFSD) was launched on November 4, 2008, only 178 days after the Wenchuan Earthquake (Xu and Li 2010). The Wenchuan Earthquake $(M w 7.9)$ produced two major surface rupture zones along the Yingxiu-Beichuan and Anxian-Guanxian faults. The Yingxiu-Beichuan Fault crosses heavily populated regions and is associated with destructive earthquakes. The first borehole (WFSD-1) of the project was drilled to investigate the mechanism of the southern segment of the Yingxiu-Beichuan Fault (Li et al. 2012).

In recent studies, fault zone structures have been observed, and friction experiments and rock magnetic 
measurements have been performed on surface samples in the area of the Yingxiu-Beichuan Fault (Lin et al. 2010; Verberne et al. 2010; Togo et al. 2011a, b). The internal structures of the Beichuan fault zone in the outcrop at Hongkou demonstrate that the Beichuan fault zone consists of fault breccias, cataclasite, and fault gouge, although there are differences in descriptions of the width of the fault gouge zone (Lin et al. 2010; Togo et al. 2011a; Wang et al. 2014). Friction experiments proved that the clay-rich sediments of the region might have a damping effect upon ruptures propagating from depth (Verberne et al. 2010). High-velocity friction experiments performed on the Hongkou outcrop clayey fault gouge showed that this rock exhibits dramatic weakening at seismic slip rates, and the steady-state frictional coefficient reduces to as low as 0.1 to 0.2 at a slip rate of $1.3 \mathrm{~m} / \mathrm{s}$ (Togo et al. 2011b).

Rock magnetic measurements from Zhaojiagou and Dagou showed that the magnetic properties of most of the fault rocks are dominated by paramagnetic components. Although magnetic susceptibility measurements from the Zhaojiagou section showed insignificant anomalies in the gouge, the results from the Zhaojiagou outcrop fault rock measurements suggested that the temperature had been high enough to drive the decomposition of Febearing minerals to form magnetite or maghemite (Yang et al. 2012a, b, 2013; Liu et al. 2014). Preliminary magnetic susceptibility measurement results of the WFSD-1 borehole core (but only within the fault zones) were reported by Pei et al. (2010), but results for all core samples have not yet been published. In particular, in the WFSD-1 borehole, the high magnetic susceptibility patterns obtained from logging data near the primary slip zone of the Wenchuan Earthquake look similar to the pattern at a single fault zone seen at a small scale. There may be a larger-scale high magnetic susceptibility anomaly in the Yingxiu-Beichuan Fault Zone.

All samples from the WFSD-1 borehole underwent preliminary study in the WFSD field laboratory shortly after drilling. They were also studied later using several methods to obtain a complete set of data on the petrophysical, geochemical, and lithological properties (Li et al. 2012).

In this paper, we report the results of the magnetic susceptibility measurements for all core samples of the WFSD-1 borehole, present the magnetic susceptibility characteristics of the core samples, and discuss the difference between the core measurements and the logging data. We also assess the processes that caused the high magnetic susceptibility in the fault gouge by analyzing selected core samples from the primary slip zone in the WFSD-1 borehole. Finally, we discuss the implications of the presence of multi-segment fault rocks with high magnetic susceptibility in the WFSD-1 core.

\section{Geological setting and drilling procedure}

Longmen Shan is the main mountain range along and one of the steepest margins of the eastern edge of the Tibetan Plateau in Sichuan Province, China. The significant deformation in western Sichuan has been governed by interactions among three crustal blocks (Songpan, Chuandian, and South China) (Figure 1). The Longmen Shan thrust belt consists of the Wenchuan-Maoxian, Yingxiu-Beichuan, and Anxian-Guanxian faults, at the eastern margin of the Tibetan Plateau (e.g., Burchfiel et al. 2008; Densmore et al. 2007). These faults show long-term activity, and active faults have developed along previous faults since the late Triassic (Deng et al. 1994; Burchfiel et al. 1995; Li et al. 2006; Densmore et al. 2007; Xu et al. 2008). The Wenchuan Earthquake (Mw7.9, May 12, 2008) is the largest inland earthquake to have hit southwest China during the past century. Two surface ruptures extend along the northeast, striking Yingxiu-Beichuan and Anxian-Guanxian faults. Most studies found the length of the co-seismic surface rupture to be 200 to $240 \mathrm{~km}$ (e.g., Liu-Zeng et al. 2009; Xu et al. 2009; Zhang et al. 2010). However, as the 2008 Wenchuan Earthquake ruptured the Qingchuan Fault, the total length of the rupture zone is approximately $275 \mathrm{~km}$ (Xu et al. 2008; Li et al. 2008), possibly even as much as 285 to $300 \mathrm{~km}$ (Lin et al. 2012).

The first borehole, WFSD-1, was drilled 178 days after the earthquake through 1,201.15 m of the Neoproterozoic Pengguan complex and the alternating sandstones and siltstones of the Triassic Xujiahe Formation. The borehole is located along the southern segment of the Yingxiu-Beichuan Fault, and designed to be an inclined borehole, with an $80^{\circ}$ inclination angle in a $134^{\circ} \mathrm{NE}$ direction. The borehole recovered 1,368.29 $\mathrm{m}$ of core sample (Li et al. 2012). The borehole consists of three segments, 32.17 to $304.26 \mathrm{~m}, 179.85$ to $625.80 \mathrm{~m}$, and 583.07 to $1,201.15 \mathrm{~m}$, due to drilling accidents at depths of 304.26 and $625.80 \mathrm{~m}$ (Fan et al. 2009). Two general rock types are found in the borehole cores. Unit 1 is the Pengguan complex, consisting of gray-green diorite, volcanic rocks, and pyroclastic rocks, with ages of 850 to $750 \mathrm{Ma}$ (Yan et al. 2004). This unit is the hanging wall of the Yingxiu-Beichuan Fault and is found at depths shallower than $585.75 \mathrm{~m}$. Pseudotachylyte has been found in an outcrop near the boundary of the Pengguan complex and the Xujiahe Formation, but does not occur in this borehole (Li et al. 2014; Wang et al. 2014). Unit 2 is the Triassic Xujiahe Formation, which consists of gray sandstone, siltstone, and dark gray mudstone with coal beds. This is the footwall of the fault and is found below depths of $598 \mathrm{~m}$.

On the basis of the fault rock distribution and fault density, 12 fault zones with fault gouge, cataclastic rocks, and fault breccias have been identified within the 


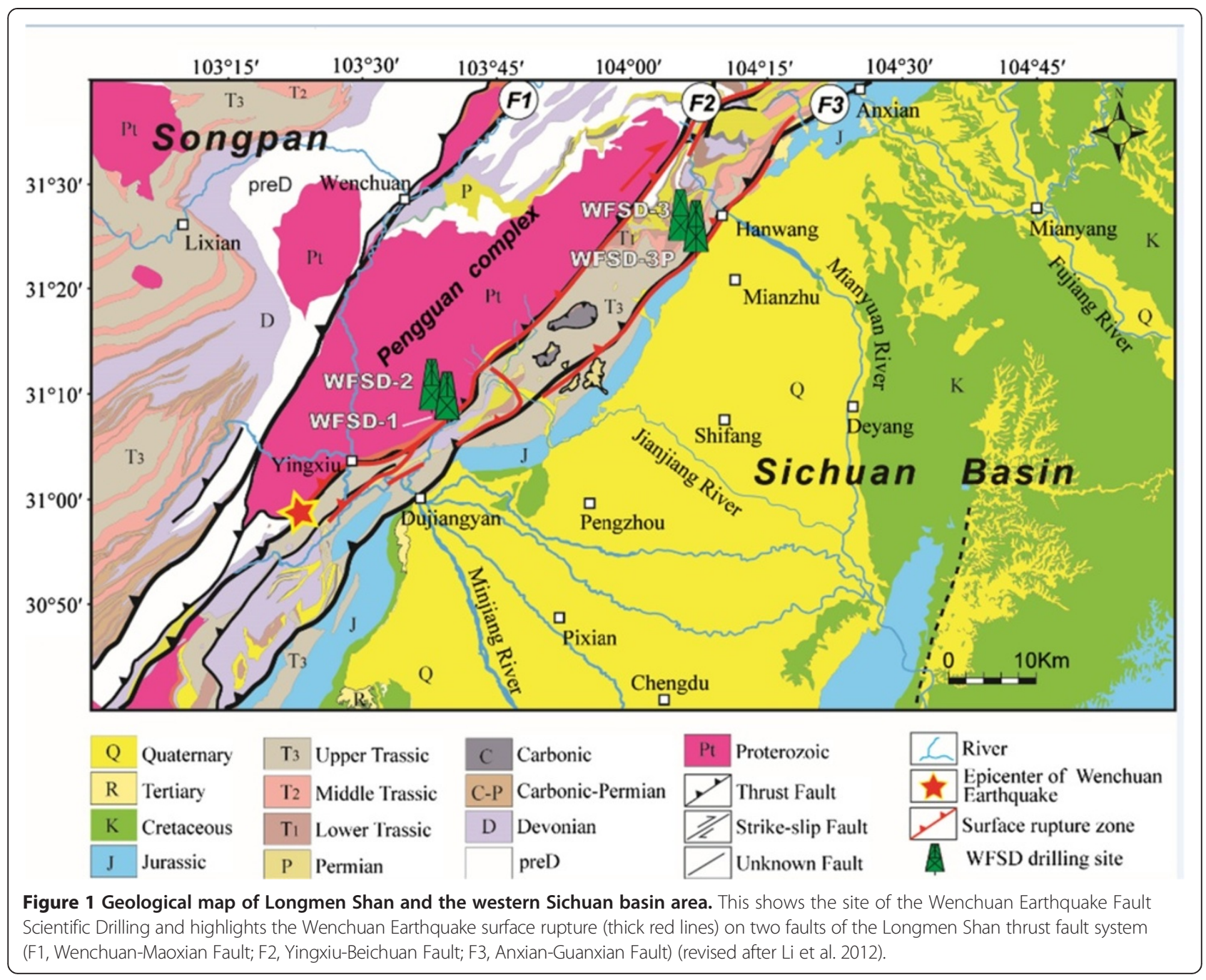

WFSD-1 core (Li et al. 2012). The scale of these fault zones ranges from a few centimeters to tens of meters. The thickest fault zone occurs between 585 and $598 \mathrm{~m}$. The fault zones containing significant fault gouge are FZ233 (from 232.2 to 233.9 m), FZ590 (from 575.7 to $595.5 \mathrm{~m}$ ), and FZ759 (from 753.13 to $759 \mathrm{~m}$ ). From the analysis of core observations and measurements of physical properties, Li et al. (2012) identified the principal slip zone (PSZ) of the Wenchuan Earthquake as having been at FZ590.

\section{Methods}

Magnetic susceptibility was measured on all core surfaces at 1-cm intervals using a Bartington MS2E surface sensor (Witney, Oxon, England). The active region of the MS2E sensor is at the end of a $25-\mathrm{mm}$ diameter ceramic cylinder mounted in line with the electronics unit. The active region of the sensing surface is a $10.5 \times 3.8-\mathrm{mm}$ rectangle.

The results include three sections named WFSD-1-1 (32.17 to $304.26 \mathrm{~m}$ ), WFSD-1-S1 (179.85 to $625.80 \mathrm{~m}$ ), and WFSD-1-S2 (583.07 to $1,201.15 \mathrm{~m}$ ) due to the down borehole drilling accidents at 304.26- and 625.80-m depths (Fan et al. 2009). The results for WFSD-1-S1a come from the same core as WFSD-1-S1, but include iron contamination. The drilling tool debris can be easily removed with forceps (Figure 2).

The magnetic susceptibility variation patterns of WFSD1-1 from 179.85 to $304.26 \mathrm{~m}$ resemble those from the same depth interval in WFSD-1-S1, and the variations from 583.07 to $625.80 \mathrm{~m}$ in WFSD-1-S1 resemble the same depth interval in WFSD-1-S2, except for the abnormally high values at depths of approximately 594.2 and $629 \mathrm{~m}$ (Figure 3). The magnetic susceptibility of the WFSD-1 borehole includes all of WFSD-1-1, 304.26 to $625.80 \mathrm{~m}$ of WFSD-1-S1, and 625.80 to $1,201.15 \mathrm{~m}$ of WFSD-1-S2 (Figure 3).

The main damaged zone in the FZ590 fault zone consists of at least 12 layers of fault gouges, but the darkest layer of the gouge, including the PSZ position of the Wenchuan Earthquake, can only be seen in one layer 


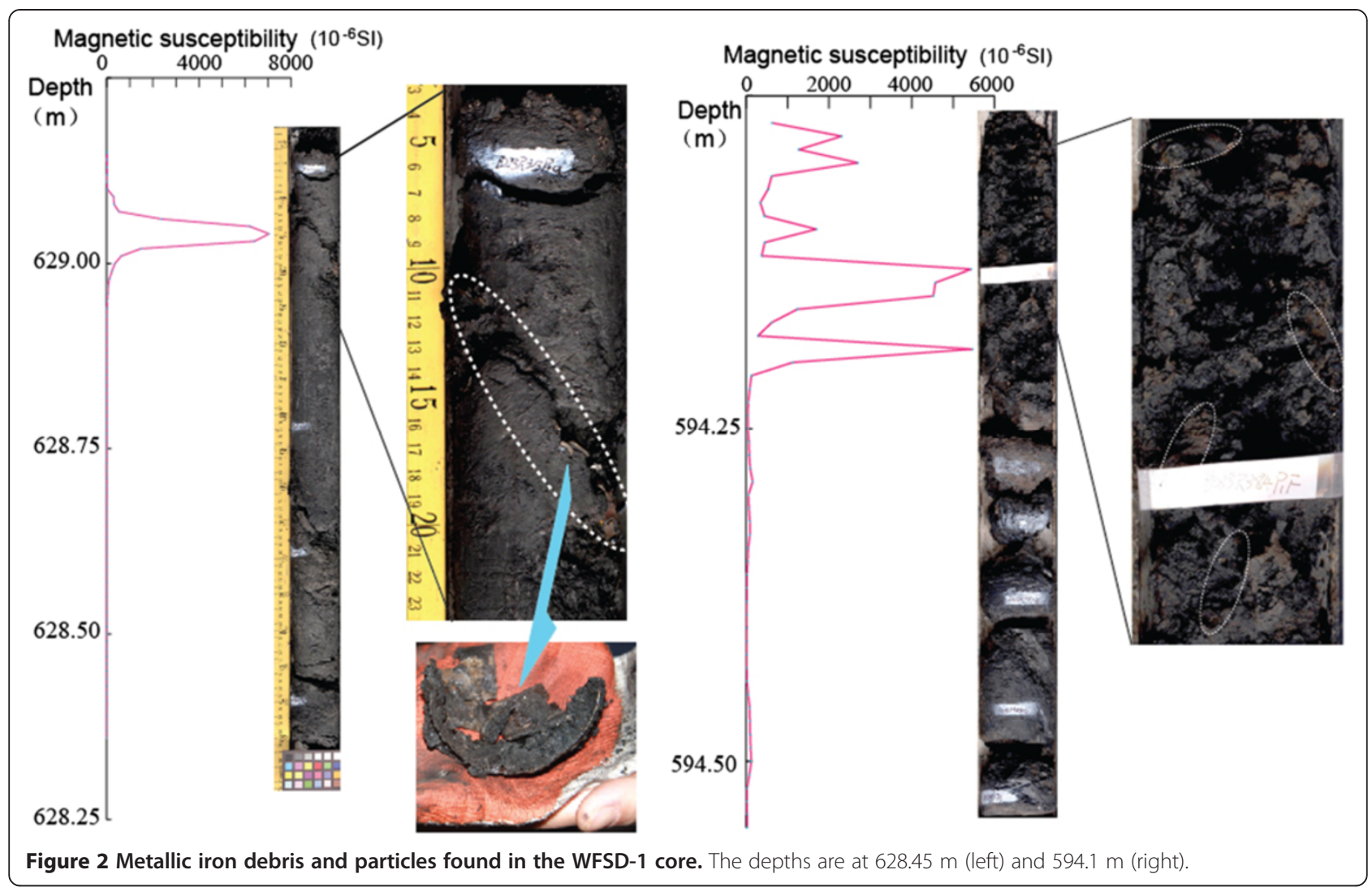

(589.17- to 589.28-m depth), which seems to be the freshest (Figure 3, Li et al. 2012). To understand the high magnetic susceptibility in FZ590, we took six samples within every $10-\mathrm{cm}$ interval between depths of 589.05 and $589.55 \mathrm{~m}$. Thermomagnetic curves $(k-T)$ and mass magnetic susceptibility were measured using a Kappabridge (KLY-4, AGICO, Brno, Czech Republic) with a CS-3 high-temperature furnace at the Key Laboratory of Paleomagnetism and Tectonic Reconstruction of the Ministry of Land and Resources, China. Thermomagnetic measurements were conducted in an argon atmosphere and in air, while applying a steady field of $300 \mathrm{~A} / \mathrm{m}$. The samples were heated to $700^{\circ} \mathrm{C}$ and then cooled to room temperature at a rate of $10^{\circ} \mathrm{C} / \mathrm{min}$.

Magnetic hysteresis loops were measured with an alternating gradient magnetometer (Princeton Micromag 2900, Westerville, OH, USA) at the physics laboratory of Beijing University. The magnetic field was cycled between $\pm 1.0 \mathrm{~T}$. Saturation magnetization $(\mathrm{Ms})$, saturation remanence (Mrs), and magnetic coercivity (Hc) were determined after correction for the paramagnetic contribution. Coercivity of remanence (Hcr) is the field required to erase remanent magnetization permanently; it was obtained by backfield measurements after being magnetized at $1.0 \mathrm{~T}$.

The mass magnetic susceptibility of these six samples ranges from $3.42 \times 10^{-8}$ to $10.54 \times 10^{-8} \mathrm{~m}^{3} / \mathrm{kg}$. The 589.25-m-depth sample is the highest in magnetic susceptibility, which is similar to the pattern obtained from the surface measurements of the core. The $k-T$ curves can help identify magnetic materials (Deng et al. 2001). The $k$ - $T$ curves of the selected samples from the FZ590 display a rapid increase in slope after $380^{\circ} \mathrm{C}$, and a marked peak occurs at about $510^{\circ} \mathrm{C}$ in the heating curves. The magnetic susceptibility becomes effectively zero at about $585^{\circ} \mathrm{C}$ (Figure 4). All the cooling curves show a clear hump between $580^{\circ} \mathrm{C}$ and $380^{\circ} \mathrm{C}$, the value of which is obviously higher than that of the peak in the heating curves.

\section{Results and discussion}

\section{Iron contamination}

In the WFSD-1 borehole, the high magnetic susceptibility values obtained from logging data near the primary slip zone, between the depths of 505 and $590 \mathrm{~m}$ and the depths of 675 and $695 \mathrm{~m}$, seen on a larger scale, look similar to the patterns observed at a single fault zone on a small scale (e.g., the magnetic susceptibility at depths of approximately 589.25, 618, 730, and $732.5 \mathrm{~m}$ ) (Figure 5). The results for the magnetic susceptibility of the core and logging data are consistent, except for depths between 500 and $700 \mathrm{~m}$ (Figure 5).

This significant difference between the core and logging magnetic susceptibility data requires explanation. 


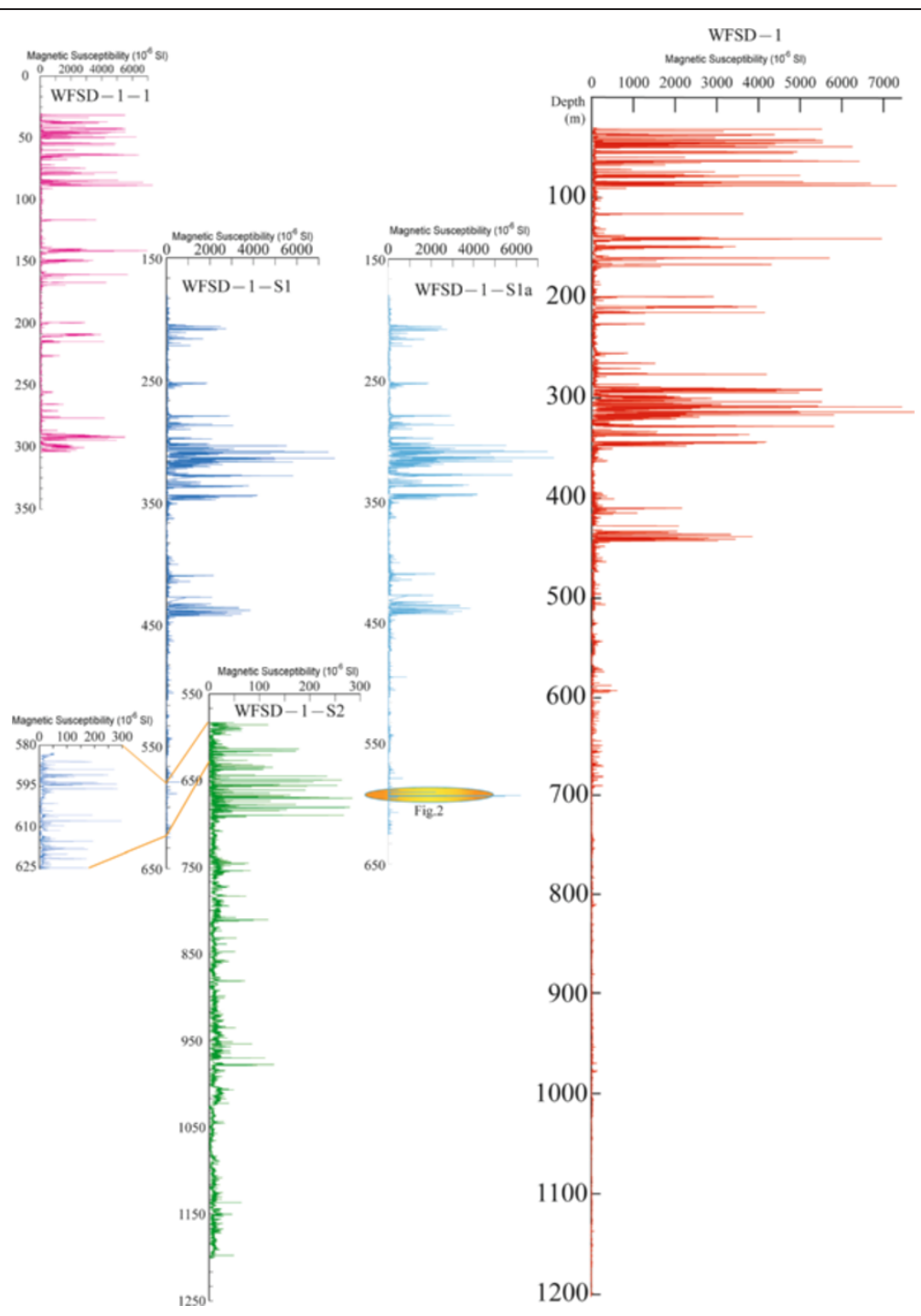

Figure 3 The magnetic susceptibility of the WFSD-1 borehole. The oval indicates an area of high magnetic susceptibility caused by iron debris from the drilling accidents in Figure 2.

Some metallic iron debris was found in this borehole core during analysis around 628.45- and 594.1-m depths (Figure 2). It is also noteworthy that drilling accidents occurred at 590.76- and 625.80-m depths, and drilling was resumed in a separate borehole at $583.07 \mathrm{~m}$ (Fan et al. 2009). There are significant amounts of metal particles near 590.76-m depth caused by milling of the lost drill, and some abandoned metal instruments around 625.80-m depth. The significant magnetic susceptibility anomalies in the logging data at depths between 500 and $700 \mathrm{~m}$ are caused by these metallic iron particles that originated from the drilling accident.

Relationship between magnetic susceptibility and lithology Granite and volcanic rocks make up most of the Neoproterozoic Pengguan complex, which occurs above 585-m depth in the WFSD-1 core. Pyroclastics, mainly consisting of celadon tuff, are present from 3- to 181.5$\mathrm{m}$ depth. The main rock types from 181.5- to 291-m depths are porphyries and diorite, with three intervals of volcanic rocks: 189 to $196 \mathrm{~m}, 226$ to $249 \mathrm{~m}$, and 271 to $276 \mathrm{~m}$. Between depths of 291 and $575.6 \mathrm{~m}$, mostly volcanic rocks and pyroclastics occur, except for three intervals of diorite and porphyries located at 362.7 to $394 \mathrm{~m}, 494$ to $512 \mathrm{~m}$, and 545 to $555 \mathrm{~m}$ (Li et al. 2012).

The surface magnetic susceptibility values of the Pengguan complex range from hundreds to thousands of $10^{-6} \mathrm{SI}$, consistent with the great variations in lithology (Figures 5 and 6a). The lithology of the core between about 598- and 759-m depth is mainly gray sandstone, dark-gray siltstone, carbon shale, and coal bed. Below $759 \mathrm{~m}$, the rocks are mainly gray sandstone, dark- 


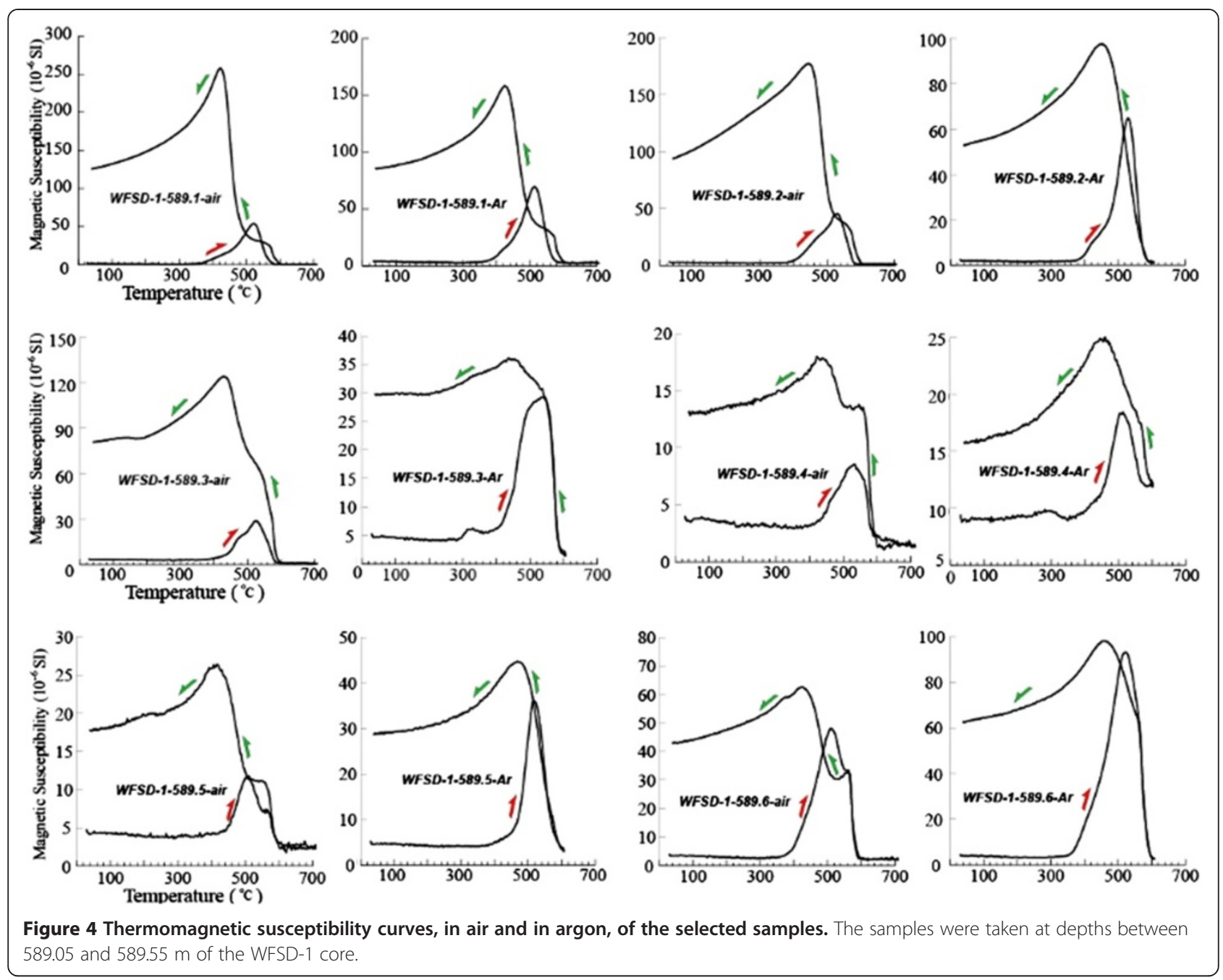

colored fine sandstone, and liquefied breccias ( $\mathrm{Li}$ et al. 2012).

The surface magnetic susceptibility values of the Xujiahe Formation usually range from a few to dozens of $10^{-6}$ SI (Figure $6 \mathrm{~b}, \mathrm{~d}$ ), and the carbon shale and coal bed rocks from zero to $<10 \times 10^{-6}$ SI (Figure 6c). Furthermore, the liquefied breccia segment cores are composed of gray sandstone and black siltstone, which may be seismites resulting from intense and strong earthquakes during the late Triassic. Higher values are associated with the black siltstone, and lower values with the gray sandstone in these segments (Figure 6e).

The magnetic susceptibility of a rock is strongly influenced by its concentration of ferrimagnetic minerals, mainly iron oxides such as magnetite, titanomagnetite, and hematite (Dunlop and Orzdemir 1997). On the whole, the lithology of the WFSD-1 core controls the pattern of the magnetic susceptibility variance. However, the large variations in magnetic susceptibility may not have been caused only by lithological changes (Figure 5).

\section{Relationship between magnetic susceptibility and fault} rocks

Correlations between magnetic susceptibility anomalies and the occurrence of cataclastic zones and faults have been reported (Bosum et al. 1997). Recently, a number of examples of high magnetic susceptibility within fault gouges have been described from several faults related to large earthquakes (Enomoto and Zheng 1998; Nakamura and Nagahama 2001; Fukuchi et al. 2005; Hirono et al. 2006; Mishima et al. 2006, 2009). Similarly, some core gouges with high magnetic susceptibility occur within the WFSD-1 core.

In this paper, we present the results obtained from the fault rocks at depths of approximately 589.25, 618, 709, 730 , and $732.5 \mathrm{~m}$ (Figure 7). These sections contain fault gouges, cataclasite, and host rock. The 589.25-m-depth gouge was generated during the 2008 Wenchuan Earthquake (Li et al. 2012). The magnetic susceptibility of this section shows a significant peak corresponding to the fresh black gouge (Figure $7 \mathrm{~b}$ ). In addition, some fault 


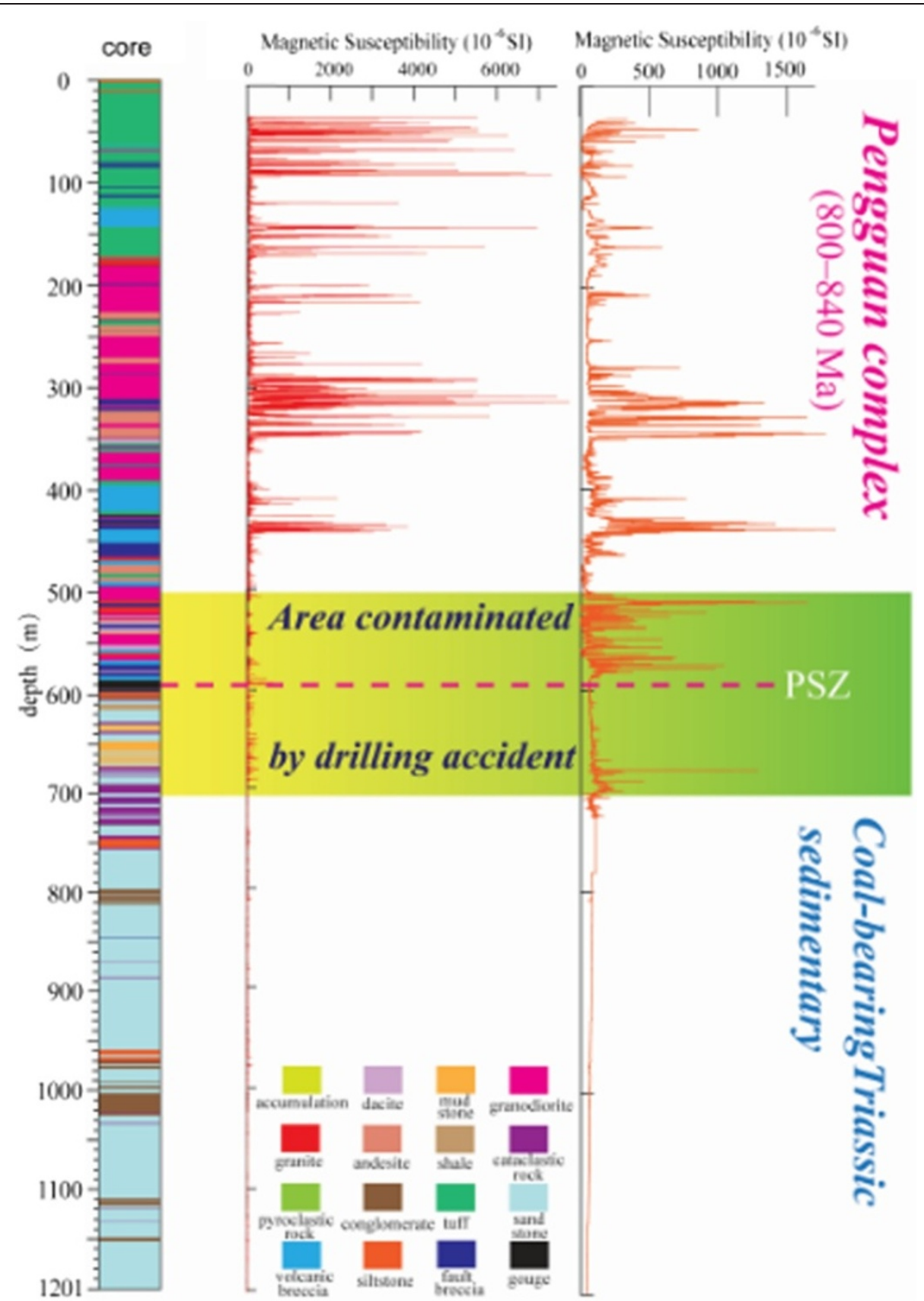

Figure 5 Depth logs. This shows the simplified lithology (left) and magnetic susceptibility of the core and logging data (right) of the WFSD-1 borehole.

gouges are regarded as ancient slip zones because of their hardened features showing distinct highs in magnetic susceptibility (Figure 7c,d,f). However, lower magnetic susceptibilities corresponding to cataclasite or fault breccias also occur in the WFSD-1 borehole (Figure 7e). Moreover, insignificant anomalies were revealed from some fault gouges of the WFSD-1 core (Figure 7a) and sections in the outcrop, including fault gouges and immediate host rocks at the Yingxiu-Beichuan Fault (Yang et al. 2012a, b, 2013). A possible reason for the insignificant variation in magnetic susceptibility of fault rocks (gouge) occurring in outcrop is that high magnetic susceptibility magnetic minerals (e.g., magnetite) transform into low magnetic susceptibility mineral assemblages as a result of surface processes such as weathering, microbial processes, and oxidation-reduction (Liu et al. 2014). Although a correlation between the magnetic susceptibility anomalies and the fault rock (fault gouge) 


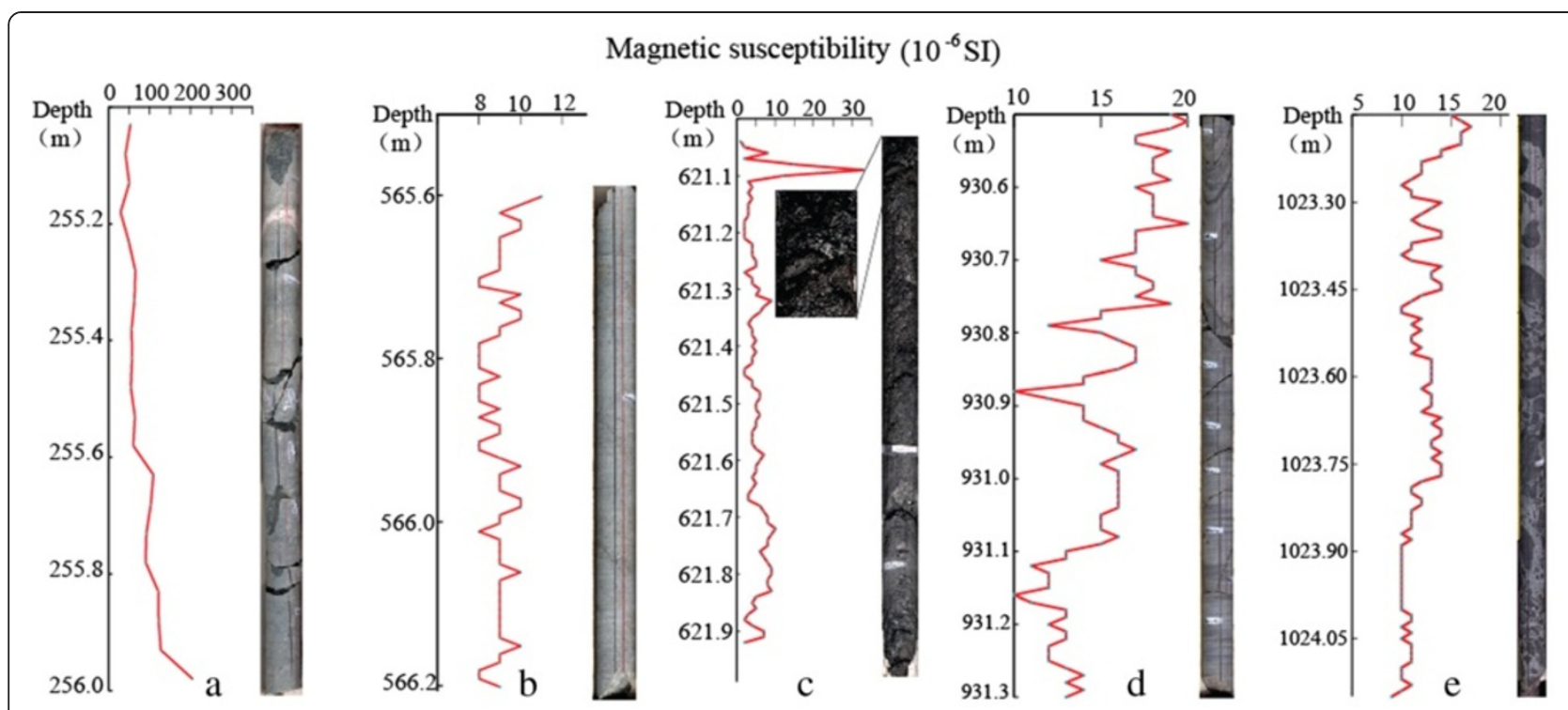

Figure 6 Magnetic susceptibility and lithological sequence of the WFSD-1 core, showing the correlation between the two. (a) Pengguan complex, (b) gray sandstone, (c) dark-gray siltstone with carbon shale, (d) gray and dark-gray siltstone, and (e) black siltstone and gray sandstone.

occurrences is present in the WFSD-1 borehole, not all rocks with higher magnetic susceptibility are fault rocks; mafic intrusions can cause similar variations (Ferré et al. 2009). There is another possibility which is that faults can occur in places where the rocks on either side have different compositions, resulting in contrasting magnetic susceptibilities. Therefore, only cases in which high magnetic susceptibility fault rocks (fault gouge) occur in the same country rock can be considered as indicators of earthquakes or seismic signatures.

\section{Mechanism of the magnetic susceptibility enhancement at the Wenchuan Earthquake PSZ and its implications}

The results of the mass magnetic susceptibility confirm the high values at the PSZ of the Wenchuan Earthquake near 589.25-m depth (Figure 8i). The mechanism for susceptibility enhancement of fault gouges is still a subject for debate. The anomalies of the Chi-Chi earthquake are, in general, caused by increased amounts of ferrimagnetic minerals in the rocks (Mishima et al. 2009; Chou et al. 2012).

The $k-T$ curves of the FZ590 samples show a Curie temperature near $580^{\circ} \mathrm{C}$, a cooling curve above the heating curve, and a hump above $380^{\circ} \mathrm{C}$ during heating. The magnetic hysteresis experiments show the existence of paramagnetic minerals (Figure 8a,b,c,d,e,f,g). Paramagnetic susceptibility $\left(\chi_{\text {para }}\right)$ is determined from the high-field slopes of the hysteresis curves (Table 1 and Figure 8j).

The Curie point near $580^{\circ} \mathrm{C}$ indicates that nearly-pure magnetite is the magnetic carrier (Dunlop and Özdemir 1997). The high $X_{\text {para }}$ of samples 589-1 and 589-2 indicate that the paramagnetic component is dominant in these samples, but ferrimagnetic susceptibility $\left(\chi_{\text {ferri }}\right)$ shows a similar pattern to $\chi_{\text {If }}$ (Table 1 and Figure 8k). Moreover, Ms shows a significant peak at a depth of $589.25 \mathrm{~m}$, as do $\chi_{\mathrm{lf}}$ and $\chi_{\mathrm{ferri}} ; \mathrm{Hc}$ at the $589.25-\mathrm{m}$ depth is lower than those of the other samples (Table 1 , Figure $8 \mathrm{i}, \mathrm{j}, \mathrm{k}, \mathrm{l}, \mathrm{m})$. The behavior of the heating curves above $380^{\circ} \mathrm{C}$ is probably associated with the neoformation of magnetite from iron-containing silicates/clays or pyrrhotite (Hunt et al. 1995; Deng et al. 2001; Chou et al. 2012). The high magnetic susceptibility in the $589.25-\mathrm{m}$ depth sample is directly proportional to $\chi_{\text {ferri, }}$, and the high Ms may show that new minerals with low Hc were formed during dynamic earthquake faulting. When compared to the theoretical hysteresis trends for SD-SP and SD-MD mixtures (Dunlop 2002a) on a Day diagram (Day et al. 1977), all samples display values generally parallel to the SD-MD mixing model curve (Figure 8n).

The clay minerals of the WFSD-1 PSZ of the Wenchuan Earthquake came to general attention when $\mathrm{Si}$ et al. (2010) pointed out the high smectite content, low illite and chlorite levels, and the tiny amount of kaolinite. In contrast, the fault gouge in the outcrop at the Hongkou surface rupture has high illite and chlorite contents and very little smectite content ( $\mathrm{Si}$ et al. 2010; Togo et al. 2011a). The loss of clay minerals at depth was probably caused by their conversion into magnetite by complex reactions driven by frictional heating and hot fluids injected by the thermal pressurization slip mechanism (Lin 2011). For example, oxidized alteration of chlorite forms some iron oxides (Chamberlain et al. 1999), and siderite changes into pyrite and magnetite under low-oxygen conditions (Tanikawa et al. 2008). 


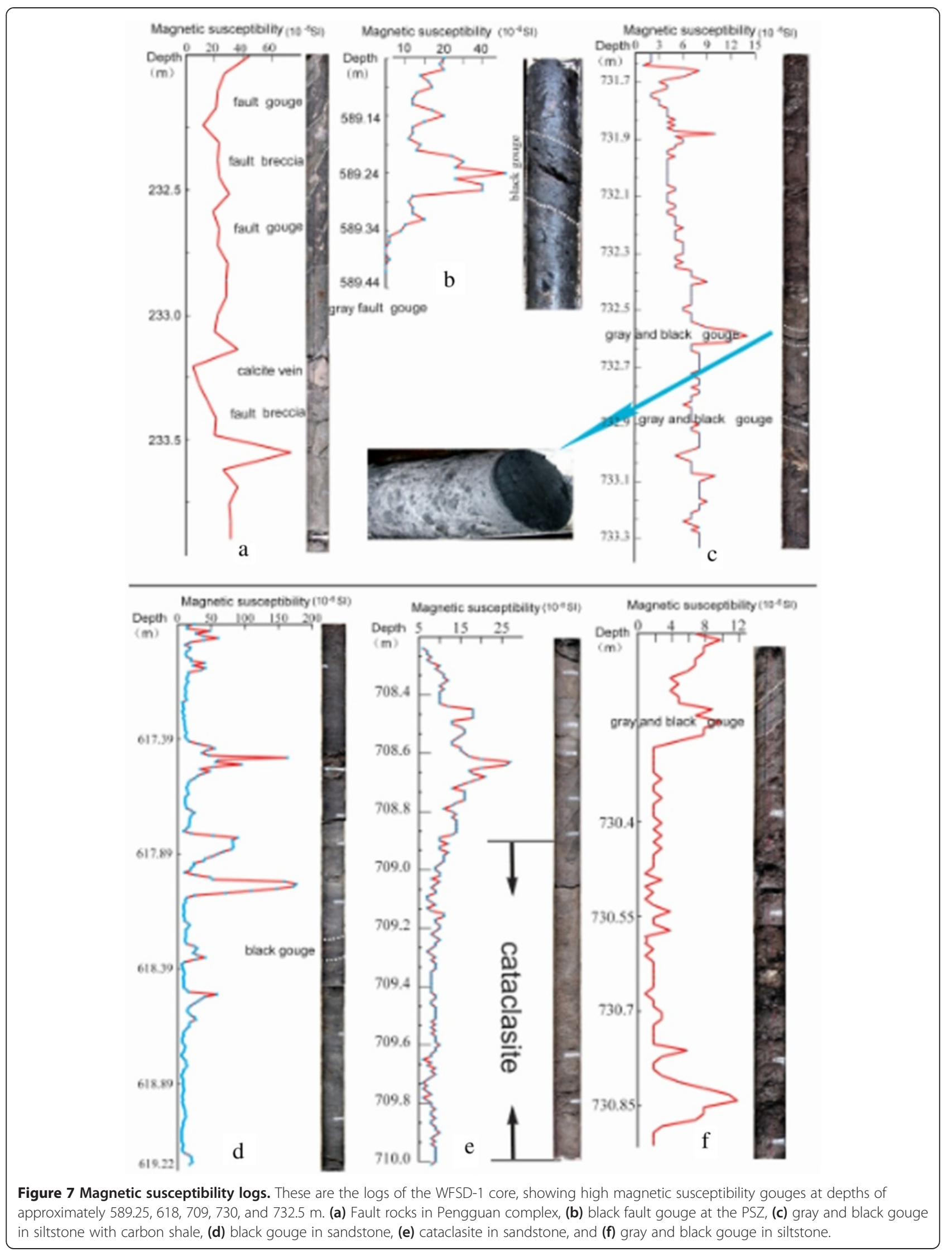




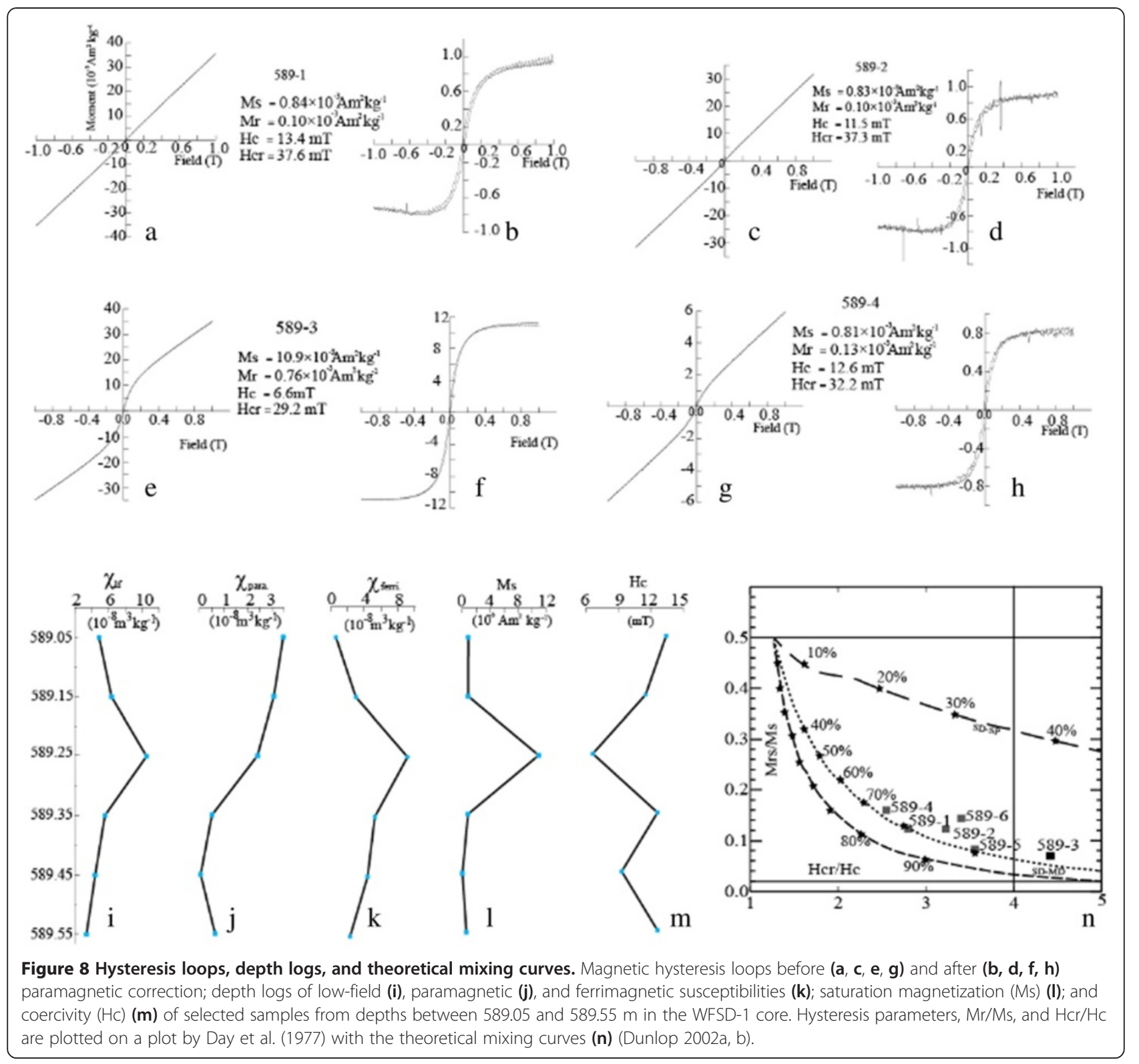

Table 1 Magnetic parameters of the selected samples from depths of 589.05 to $589.55 \mathrm{~m}$ in WFSD-1

\begin{tabular}{|c|c|c|c|c|c|c|c|}
\hline Sample & $X_{\text {If }}\left(10^{-8} \mathrm{~m}^{3} / \mathrm{kg}\right)$ & $X_{\text {para }}\left(10^{-8} \mathrm{~m}^{3} / \mathrm{kg}\right)$ & $X_{\text {ferri }}\left(10^{-8} \mathrm{~m}^{3} / \mathrm{kg}\right)$ & $\mathrm{Ms}\left(10^{-3} \mathrm{Am}^{2} / \mathrm{kg}\right)$ & $\operatorname{Mrs}\left(10^{-3} \mathrm{Am}^{2} / \mathrm{kg}\right)$ & $\mathrm{Hc}(\mathrm{mT})$ & $\operatorname{Hcr}(\mathrm{mT})$ \\
\hline 589-1 & 4.92 & 3.47 & 1.45 & 0.844 & 0.102 & 13.4 & 37.6 \\
\hline $589-2$ & 6.39 & 3.08 & 3.31 & 0.825 & 0.101 & 11.5 & 37.3 \\
\hline $589-3$ & 10.54 & 2.40 & 8.14 & 10.916 & 0.760 & 6.59 & 29.2 \\
\hline 589-4 & 5.60 & 0.51 & 5.09 & 0.804 & 0.126 & 12.6 & 32.2 \\
\hline $589-5$ & 4.45 & 0.04 & 4.41 & 0.011 & 0.001 & 9.29 & 33.8 \\
\hline $589-6$ & 3.42 & 0.65 & 2.77 & 0.560 & 0.079 & 12.6 & 42.7 \\
\hline
\end{tabular}

$X_{\mathrm{If}}$ low field magnetic susceptibility; $X_{\text {para, }}$ paramagnetic susceptibility verified by hysteresis measurements; $X_{\mathrm{ferri}}$ ferrimagnetic susceptibility calculated from the difference between $X_{\text {If }}$ and $X_{\text {parai }} \mathrm{Ms}$, saturation magnetization; Mrs, saturation remanence; $\mathrm{Hc}$, coercivity; Hcr, coercivity of remanence. 
The principal mechanism responsible for the 589.25m-depth high magnetic susceptibility might have been the production of new magnetite from iron-containing silicates (e.g., chlorite) or clays caused by frictional heating during seismic slip (Yang et al. 2012a). The presence of several layers of fault gouge with high magnetic susceptibility in the WFSD-1 borehole indicates that large earthquakes have occurred repeatedly on the YingxiuBeichuan fault.

\section{Conclusions}

High-resolution measurements revealed detailed variations in the magnetic susceptibility of the WFSD-1 core. The reason that the results of the core surface measurement and the logging data are obviously different for depths between 500 and $700 \mathrm{~m}$ is that drilling accidents produced significant amounts metallic iron debris.

In general, the rock types control the greatest proportion of the magnetic susceptibility. The magnetic susceptibility values of the hanging wall (the Pengguan complex) range from dozens of to several hundred $10^{-6}$ SI, and the values for the footwall (the Xujiahe Formation) usually range from a few to dozens of $10^{-6} \mathrm{SI}$. Moreover, possible correlations between the magnetic susceptibility anomalies and the occurrence of fault rocks (fault gouge) are shown by a few fault zones in the WFSD-1 core. The high values of the fault gouge at $589.25-\mathrm{m}$ depth require the formation of magnetic minerals with high magnetic susceptibility, such as magnetite. The production of new magnetite may have been from the breakdown of iron-containing silicates or clays (e.g., chlorite) as a result of the higher temperatures caused by frictional heating during a large earthquake.

Fault gouges with high magnetic susceptibility in the same wall rocks can be considered as a proxy for earthquakes or seismic signatures. That multi-segment fault rocks with high magnetic susceptibility which occur in the WFSD-1 core indicate that repeated seismic activity has taken place on the Yingxiu-Beichuan Fault.

Questions remain, however, whether the high magnetic susceptibility fault gouges were formed by one earthquake; whether the fault gouges of different depths, such as surface outcrop and the drilling core, are of a similar nature; and why the magnetic susceptibility of some fault gouges does not display a significant anomaly. The rock magnetic properties of the WFSD-1 core for different rock types and fault zones will be addressed in future studies.

\section{Competing interests}

The authors declare that they have no competing interests.

\section{Authors' contributions}

JP conceived of the study, carried out the magnetic measurements, and drafted the manuscript. HL participated in its design and coordination. HW participated in the design of the study and carried out the magnetic susceptibility measurements. JS carried out the field works and magnetic susceptibility measurements. ZS participated in the statistical analysis. ZZ performed the rock magnetic measurements. All authors read and approved the final manuscript.

\section{Acknowledgements}

We thank the Wenchuan Earthquake Faults Scientific Drilling Centre for their help. The authors also thank the 403 geological survey teams for their field drilling work and well logging. We are particularly grateful to Eric C. Ferré and an anonymous reviewer for many useful and important comments, and Toshi Yamazaki for editorial help. The authors would like to thank Liu Ankun and Enago (www.enago.cn) for the English language review. This research was funded by the Ministry of Science and Technology of China through the 'Wenchuan Earthquake Fault Scientific Drilling Program (WFSD),' the National Science Foundation of China (grant 41172177), and basic outlay of scientific research work from the Ministry of Science and Technology (DZLXJK201308).

\section{Author details}

${ }^{1}$ Key Laboratory of Paleomagnetism and Tectonic Reconstruction of Ministry of Land and Resources, Institute of Geomechanics, Chinese Academy of Geological Sciences, Beijing 100081, China. ${ }^{2}$ State Key Laboratory of Continental Tectonic and Dynamics, Institute of Geology, Chinese Academy of Geological Sciences, Beijing 100037, China.

Received: 1 August 2013 Accepted: 13 November 2013

Published: 28 April 2014

\section{References}

Bosum W, Casten U, Fieberg FC, Heyde I, Soffel HC (1997) Three-dimensional interpretation of the KTB gravity and magnetic anomalies. J Geophys Res 102 (B8):18307-18321

Burchfiel BC, Chen ZL, Liu Y, Royden LH (1995) Tectonics of the Longmen Shan and adjacent regions, Central China. Int Geol Rev 37(8):661-735

Burchfiel BC, Royden LH, Van der Hilst RD, Hager BH, Chen Z, King RW, Li C, Lü J, Yao H, Kirby E (2008) A geological and geophysical context for the Wenchuan Earthquake of 12 May 2008, Sichuan, People's Republic of China. GSA Today 18:4-11

Chamberlain CP, Poage MA, Craw D, Reynolds RC (1999) Topographic development of the Southern Alps recorded by the isotopic composition of authigenic clay minerals, South Island. New Zealand Chem Geol 155:279-294

Chou YM, Song SR, Aubourg C, Lee TQ, Boullier AM, Song YF, Yeh EC, Kuo LW, Wang CY (2012) An earthquake slip zone is a magnetic recorder. Geology 40:551-554

Day R, Fuller M, Schmidt VA (1977) Hysteresis properties of titanomagnetites: grainsize and compositional dependence. Phys Earth Planet Inter 13:260-267

Dearing J (1999) Magnetic susceptibility. In: Walden J, Oldfield F, Smith J (eds) Environmental magnetism: a practical guide. Quaternary Research Association, London, pp 35-62

Deng QD, Chen SF, Zhao XL (1994) Tectonics, seismicity, and dynamics of the Longmen Shan Mountains and its adjacent regions. Seismol Geol 16(4):389-403 (in Chinese with English abstract)

Deng CL, Zhu RX, Jackson MJ, Verosub KL, Singer MJ (2001) Variability of the temperature-dependent susceptibility of the Holocene eolian deposits in the Chinese loess plateau: a pedogenesis indicator. Phys Chem Earth A 26(11-12):873-878

Densmore AL, Ellis MA, Li Y, Zhou R, Hancock GS, Richardson N (2007) Active tectonics of the Beichuan and Pengguan Faults at the Eastern Margin of the Tibetan Plateau. Tectonics 26(4):TC4005, doi:10.1029/2006TC001987

Dunlop DJ (2002a) Theory and application of the Day plot: 1. Theoretical curves and tests using titanomagnetite. J Geophys Res 107(B3):EPM 4-1-EPM 4-22, doi:10.1029/2001JB000486

Dunlop DJ (2002b) Theory and application of the Day plot: 2. Application to data for rocks, sediments, and soils. J Geophys Res 107(B3):EPM 5-1-EPM 5-15, doi:10.1029/2001JB000487

Dunlop DJ, Ǒzdemir O (1997) Rock magnetism, fundamentals and frontiers. Cambridge University Press, Cambridge

Enomoto Y, Zheng Z (1998) Possible evidences of earthquake lightning accompanying the 1995 Kobe earthquake inferred from the Nojima fault gouge. Geophys Res Lett 25(14):2721-2724 
Fan LS, Jia J, Wu JS, Zhao YG, You JW (2009) Overview on drilling operation of the WFSD-1 in Wenchuan Earthquake Fault Scientific Drilling Project. Exploration Eng 36(12):5-8 (in Chinese with English abstract)

Ferré EC, Zechmeister M, Geissman J, MathanaSekaran N, Kocak K (2005) The origin of high magnetic remanence in fault pseudotachylytes: theoretical considerations and implications for co-seismic electrical currents. Tectonophysics 402:125-139

Ferré EC, Maes M, Butak KC (2009) The magnetic stratification of layered mafic intrusions: natural examples and numerical models. Lithos 111:83-94

Ferré EC, Geissman JW, Zechmeister MS (2012) Magnetic properties of fault pseudotachylytes in granites. J Geophys Res Solid Earth 117(B1):B01106, doi:10.1029/2011JB008762

Fukuchi T, Mizoguchi K, Shimamoto T (2005) Ferrimagnetic resonance signal produced by frictional heating: a new indicator of paleoseismicity. J Geophys Res 110(B12):404, doi:10.1029/2004JB003485

Hirono T, Ikehara M, Otsuki K, Mishima T, Sakaguchi M, Soh W, Omori M, Lin WR, Yeh EC, Tanikawa W, Wang C (2006) Evidence of frictional melting from diskshaped black material, discovered within the Taiwan Chelungpu fault system. Geophys Res Lett 33:L19311, doi:10.1029/2006GL027329

Hunt CP, Subir KB, Jiamao H, Peter AS, Eric O, Weiwei S, Tungsheng L (1995) Rock-magnetic proxies of climate change in the loess-paleosol sequences of the western Loess Plateau of China. Geophys J Int 123:232-244

Li Y, Zhou RJ, Densmore AL, Ellis MA (2006) Geomorphic evidence for the late Cenozoic strike-slipping and thrusting in Longmen Mountain at the eastern margin of the Tibetan Plateau. Quaternary Sci 26(1):40-51 (in Chinese with English abstract)

Li HB, Fu XF, Van der Word J, Si JL, Wang ZX, Hou LW, Qiu ZL, Li N, Wu FY, Xu ZQ, Tapponnier P (2008) Co-seismic surface rupture and dextral-slip oblique thrusting of the Ms 8.0 Wenchuan Earthquake. Acta Geological Sinica 82 (12):1623-1643 (in Chinese with English abstract)

Li HB, Wang H, Xu ZQ, Si JL, Pei JL, Li TF, Huang Y, Song SR, Kuo LW, Sun ZM, Chevalier ML, Liu DL (2012) Characteristics of the fault-related rocks, fault zones and the principal slip zone in the Wenchuan Earthquake Fault Scientific Drilling Project Borehole-1 (WFSD-1). Tectonophysics 584:23-42

Li HB, Xu ZQ, Niu YX, Kong GS, Huang Y, Wang H, Si JL, Sun ZM, Pei JL, Gong Z, Chevalier ML, Liu DL (2014) Structural and physical properties characterization in the Wenchuan Earthquake Fault Scientific Drilling Project Borehole-1 (WFSD-1). Tectonophysics 619-620:86-100

Lin AM (2011) Seismic slip recorded in the fluidized ultracataclastic veins formed along the coseismic shear zone during the $2008 \mathrm{Mw} 7.9$ Wenchuan Earthquake. Geology 39:547-550

Lin AM, Ren Z, Kumahara Y (2010) Structural analysis of the coseismic shear zone of the 2008 MW7.9 Wenchuan Earthquake, China. J Struct Geol 32:781-791

Lin AM, Rao G, Yan B (2012) Field evidence of rupture of the Qingchuan Fault during the 2008 Mw7.9 Wenchuan Earthquake, northeastern segment of the Longmen Shan Thrust Belt, China. Tectonophysics 522-523:243-252

Liu DL, Li HB, Lee TQ, Chou YM, Song SR, Sun ZM, Chevalier ML, Si JL (2014) Primary rock magnetism for the Wenchuan earthquake fault zone at Jiulong outcrop, Sichuan Province, China. Tectonophysics 619-620:58-69

Liu-Zeng J, Zhang A, Wen L, Tapponnier P, Sun J, Xing X, Hu G, Xu Q, Zeng L, Deng L, Ji C, Hunnut KW, Van Der Woerd J (2009) Co-seismic surface ruptures of the 12 May 2008 Ms 8.0 Wenchuan Earthquake, Sichuan: east-west crustal shortening on oblique, parallel thrusts along the eastern edge of Tibet. Earth Planet Sci Lett 286:355-370

Mishima T, Hirono T, Soh W, Song SR (2006) Thermal history estimation of the Taiwan Chelungpu fault using rock-magnetic methods. Geophys Res Lett 33:L23311, doi:10.1029/2006GL028088

Mishima T, Hirono T, Nakamura N, Tanikawa W, Soh W, Song SR (2009) Changes to magnetic minerals caused by frictional heating during the 1999 Taiwan Chi-Chi earthquake. Earth Planets Space 61:797-801

Nakamura N, Nagahama H (2001) Changes in magnetic and fractal properties of fractured granites near the Nojima Fault, Japan. Island Arc 10:486-494

Pei JL, Li HB, Sun ZM, Wang H, Si JL (2010) Fault slip in the Wenchuan Earthquake fault zone-information from fault rocks with higher magnetic susceptibility. Quaternary Sci 30(4):759-767 (in Chinese with English abstract)

Rauen A, Soffel HC, Winter H (2000) Statistical analysis and origin of the magnetic susceptibility of drill cuttings from the 9.1-km-deep KTB drill borehole. Geophys J Int 142:83-94

Si JL, Li HB, Song SR, Kuo LW, Pei JL, Wang H (2010) Clay mineral anomalies in WFSD Drilling Core and Surface Fault Rocks and their significances. Paper presented at the American Geophysical Unionfall annual meeting, San Francisco, CA, USA, pp 13-17, T51B-2044
Tanikawa W, Mishima T, Hirono T, Soh W, Song SR (2008) High magnetic susceptibility produced by thermal decomposition of core samples from the Chelungpu fault in Taiwan. Earth Planet Sci Lett 272(1-2):372-381

Togo T, Shimamoto T, Ma SL, Wen XZ, He HL (2011a) Internal structure of Longmenshan fault zone at Hongkou outcrop, Sichuan, China, that caused the 2008 Wenchuan Earthquake. Earthq Sci 24(3):249-265

Togo T, Shimamoto T, Ma SL, Hirose T (2011b) High-velocity frictional behavior of Longmenshan fault gouge from Hongkou outcrop and its implications for dynamic weakening of fault during the 2008 Wenchuan Earthquake. Earthq Sci 24(3):267-281

Verberne BA, He CR, Spiers C (2010) Frictional properties of sedimentary rocks and natural fault gouge from the Longmen Shan fault zone, Sichuan, China. Bull Seismol Soc Am 100(5B):2767-2790

Wang H, Li HB, Si JL, Sun ZM, Huang Y (2014) Internal structure of the Wenchuan earthquake fault zone, revealed by surface outcrop and WFSD-1 drilling core investigation. Tectonophysics 619-620:101-114

Xu ZQ, Li HB (2010) New results from the Wenchuan Earthquake Fault Scientific Drilling Project (WFSD). Paper presented at the American Geophysical Union fall meeting, San Francisco, CA, USA, pp 13-17, Abstract T53E-01

Xu ZQ, Ji SC, Li HB, Hou LW, Fu XF, Cai ZW (2008) Uplift of the Longmen Shan range and the Wenchuan Earthquake. Episodes 31(3):291-301

Xu XW, Wen XZ, Yu GH, Chen GH, Klinger Y, Hubbard J, Shaw J (2009) Coseismic reverse- and oblique-slip surface faulting generated by the 2008 Mw7.9 Wenchuan Earthquake, China. Geology 37:515-518

Yan QR, Hanson AD, Wang ZQ, Druschke PA, Yan Z, Wang T, Liu DY, Song B, Jian $P$, Zhou H, Jiang CF (2004) Neoproterozoic subduction and rifting on the Northern Margin of the Yangtze Plate, China: implications for Rodinia Reconstruction. Int Geol Rev 46(9):817-832

Yang T, Chen JY, Wang HQ, Jin HQ (2012a) Rock magnetic properties of fault rocks from the rupture of the 2008 Wenchuan Earthquake, China and their implications: preliminary results from the Zhaojiagou outcrop, Beichuan County (Sichuan). Tectonophysics 530-531:331-341

Yang T, Chen JY, Wang HQ, Jin HQ (2012b) Magnetic properties of fault rocks from the Yingxiu-Beichuan fault: constraints on temperature rise within the shallow slip zone during the 2008 Wenchuan Earthquake and their implications. J Asian Earth Sci 50:52-60

Yang T, Chen JY, Yang XS, Wang HQ, Jin HQ (2013) Differences in magnetic properties of fragments and matrix of breccias from the rupture of the 2008 Wenchuan earthquake, China: relationship to faulting. Tectonophysics 601:112-124

Zhang PZ, Wen X, Shen Z, Chen J (2010) Oblique, high-angle, listric-reverse faulting and associated development of train: the Wenchuan Earthquake of May 12, 2008, Sichuan, China. Annu Rev Earth Planet Scis 38:353-382

\section{doi:10.1186/1880-5981-66-23}

Cite this article as: Pei et al:: Magnetic properties of the Wenchuan Earthquake Fault Scientific Drilling Project Hole-1 (WFSD-1), Sichuan Province, China. Earth, Planets and Space 2014 66:23.

\section{Submit your manuscript to a SpringerOpen ${ }^{\odot}$ journal and benefit from:}

- Convenient online submission

- Rigorous peer review

- Immediate publication on acceptance

- Open access: articles freely available online

- High visibility within the field

- Retaining the copyright to your article

Submit your next manuscript at $>$ springeropen.com 